\title{
Primary antiphospholipid syndrome and antiphospholipid syndrome associated to systemic lupus: are they different entities?
}

Cristina Belizna ${ }^{1,2}$, Ljudmila Stojanovitch ${ }^{3}$, Jan Willem Cohen Tervaert ${ }^{4,5}$, Céline Fassot ${ }^{2}$, Daniel Henrion ${ }^{2}$, Laurent Loufrani ${ }^{2}$, Gyorgy Nagy ${ }^{6,7}$, Christian Muchardt ${ }^{8}$, Milena Hasan ${ }^{9}$, Marie Noelle Ungeheuer ${ }^{10}$, Laurent Arnaud ${ }^{11}$, Jaume Alijotas Reig ${ }^{12,13}$, Enrique Esteve Valverde ${ }^{14}$, Ferdinando Nicoletti ${ }^{15}$, Patrick Saulnier ${ }^{16}$, Alban Godon ${ }^{17}$, Pascal Reynier, ${ }^{2,18}$ Jean Marie Chrétien ${ }^{16}$, Laura Damian ${ }^{19}$, Loukman Omarjee ${ }^{20,21}$, Guillaume Mahé20,21, Marc Antoine Pistorius ${ }^{22},{ }^{*}$ Pier Luigi Meronii ${ }^{23},{ }^{*}$ Katrien Devreese ${ }^{24}$

*Professor K Devreese and Professor PL Meroni equally contributed to the coordination of this work.

Corresponding author : Cristina Belizna, MD, PhD, Vascular and Coagulation Department, University Hospital Angers, 4 rue Larrey, 49000 Angers, France, phone 0033241356592, mail: cristina.belizna@wanadoo.fr

\section{Declaration of interest: none.}

${ }^{1}$ Vascular and Coagulation Department, University Hospital Angers, 4 rue Larrey, 49000 Angers, France

${ }^{2}$ MITOVASC institute and CARFI facility, University of Angers, Angers, France, UMR CNRS 6015, Angers, France, INSERM U1083, rue Haute de Reculée, 49045 Angers, France.

${ }^{3}$ Scientific Research Department, Internal Medicine-Rheumatology

Bezhanijska Kosa, University Medical Center, Belgrade University, Belgrade, 11080 Serbia

${ }^{4}$ Internal Medicine and Immunology Department, Maastricht University, P Debyelaan 25, 6229 HX, Maastricht, The Netherlands

${ }^{5}$ Rheumatology Department, Kaye Edmonton Clinic University of Alberta, 116 St. and 85 Ave., Edmonton, AB, Canada T6G 2R3

${ }^{6} 3^{\text {rd }}$ Department of Internal Medicine, Rheumatology Division, Buda Hospital of the Hospitaller Order of Saint John of God, H-1023 Budapest, P.O.B. 98, Hungaria

${ }^{7}$ Semmelweis University, Department o,f Genetics, Cell- and Immunobiology, Buda Hospital of the Hospitalier Order of Saint John of God, 1089 Budapest, Nagyvárad tér 4, Hungaria

${ }^{8}$ Unit of Epigenetic Regulation, Department of Developmental and Stem Cell Biology UMR3738 CNRS, Institut Pasteur, 28, Rue Doct Roux, 75015 Paris, France

${ }^{9}$ Cytometry and Biomarkers Unit of Technology and Service, Center for Translational Science, Institut Pasteur, 28, Rue Doct Roux, 75015 Paris, France 
${ }^{10}$ Clinical Investigation and acces to bioresources department, Institut Pasteur, 28, Rue Doct Roux, 75015 Paris, France

${ }^{11}$ Rheumatology Department University Hospital Strasbourg, 1, Place de l'Hôpital, 67091 Strasbourg, France

${ }^{12}$ Systemic Autoimmune Disease Unit, Department of Internal Medicine, Vall d'Hebron University Hospital, Passeig Vall d'Hebron 119-129 08035 Barcelona, Spain

${ }^{13}$ Department of Medicine, Universitat Autonòma, Plaza Civica, 08193 Barcelona, Spain

${ }^{14}$ Internal Medicine Althaia Healthcare Network of Manresa, Calle Pau 44

08243 Manresa, Barcelona, Spain

${ }^{15}$ Department of Biomedicine and Biotechnology, University of Catania, Universita' Square, 2, 95131 Catania, Italy

${ }^{16}$ Research Department Unit University Hospital Angers, 4 rue Larrey, 49000 Angers, France

${ }^{17}$ Departement of hematology et immunology University Hospital Angers, 4 rue Larrey, 49000 Angers, France

${ }^{18}$ Departement of biochemistry and genetics University Hospital Angers, 4 rue Larrey, 49000 Angers, France

${ }^{19}$ Department of Rheumatology, County Emergency Hospital Cluj-Napoca, str. Clinicilor nr.3-5, cod postal 400006 Cluj-Napoca, Romania

${ }^{20}$ Vascular Medicine Department, University Hospital Rennes, 16, Boulevard de Bulgarie, 35203 Rennes, France

${ }^{21}$ University Rennes, CHU Rennes, INSERM, CIC 1414, 2, rue Henri Le Guilloux

35000 Rennes Cedex 9, France

${ }^{22}$ Vascular Medicine Department, University Hospital Nantes, 1, Place Alexis Ricordeau, 44093 Nantes, France

${ }^{23}$ Clinical Immunology and Rhumatology Research Department Auxologico Institute Milan, IRCCS, Via G.

Spagnoletto, 3, 20149 Milan, Italy

${ }^{24}$ Coagulation Laboratory, Department of Clinical Biology, Immunology and Microbiology, Ghent University Hospital, De Pintelaan 185, 9000 Ghent, Belgium 


\section{Abstract}

Primary antiphospholipid syndrome (PAPS) and antiphospholipid syndrome associated to lupus (SAPS) have several overlapping characteristics. As systemic manifestations are also reported in patients with PAPS, and as a subgroup of PAPS patients could evaluate to a SAPS, the differentiation between the two types of APS could be performed based on the clinical experience of the medical teams and is related to a variety of clinical, biological, histological and genetic features.

Several data are available in the literature with respect to the identification of distinctive features between these two entities. However, there are some limitation in the interpretation of results issued from studies performed prior to updated Sydney criteria.

Based on recent data, a certain number of features more frequent in one type of APS as compared to the other could be distinguished.

The major differentiation between these two entities is genetical. New genetic data allowing the identification of specific subgroups of APS are ongoing.

\section{Keywords}

Antiphospholipid syndrome, primary antiphospholipid syndrome, secondary antiphospholipid syndrome.

\section{Take-home messages}

- In primary and secondary antiphospholipid syndrome the major clinical manifestations and the biological features are similar, but they are two distinct entities with a trend for the prevalence of specific features in one and the other type.

- Differences between primary and secondary APS concern clinical and laboratory features, genetic and histological aspects.

- $\quad$ The main differences between PAPS and SAPS are related to their genetical features.

- $\quad$ Future studies on the genetic factors in APS are expected to identify specific genetic features in PAPS which evolve into SLE. 


\section{Introduction}

Antiphospholipid syndrome (APS) combines thrombotic (venous and/or arterial) and/or obstetrical manifestations, along with biological anomalies related to the presence of antiphospholipid antibodies (aPL) (circulating lupus anticoagulant, anticardiolipin antibody (aCL) or anti-ß2glycoprotein I antibody(aß2GPI)).

APS clinical-biological classification criteria were specified in 1999 and revised in 2006 (1). Diagnosis is based upon clinical and laboratory criteria. In order to define APS, at least one clinical criterion combined with at least one biological criterion are required.

Diagnostic classification criteria for APS are vascular thrombosis, pregnancy morbidity (one or more unexplained deaths of morphologically normal foetus beyond the 10th week or one or more premature births before the 34th week of gestation or three or more unexplained consecutive spontaneous abortions before the 10th week of gestation) and the presence of aPL (aCL antibodies, aß2GPI antibodies, lupus anticoagulant) (1).

Exact aetiology is unknown but is thought to be multifactorial. There is, in some families, strong evidence of a genetic component. aPL are thought to interfere with the function of binding proteins and activate endothelial cells inducing a proinflammatory and procoagulant state in blood vessels which leads to thrombosis.

The occurrence of thrombosis in patients with APS has been explained by several physiopathological hypotheses, including:

- $\quad$ activation of various cells, including endothelial cells, monocytes and platelets (2)

- $\quad$ acquired activated protein $\mathrm{C}$ resistance (3)

- $\quad$ tissue factor expression, reduced tissue factor pathway inhibitor (TFPI) (4).

- $\quad$ complement activation (5)

- $\quad$ resistance to the action of annexin A5 (6-8).

Additionally to well-known mechanisms including activation of endothelial cells, monocytes, and platelets, and/or inhibition of natural anticoagulant and fibrinolytic systems by aPL new mechanisms were recently described (9).

Therefore, the antibodies against the domain I of $\beta 2$ glycoprotein I ( $\beta 2 \mathrm{GPI}$ ) are increasingly recognized as the main pathogenic subset in APS; annexinA2 and toll-like receptor (TLR)4 have been identified as the main receptors for $\beta 2 \mathrm{GPI} / a n t i-\beta 2 \mathrm{GPI}$ antibodies on target cells, and additional co-receptors such as TLR1, TLR2 and TLR6 were reported. Upon binding, aPL trigger intracellular mediators such as nuclear factor kappa B and mammalian target of rapamycin (10-12).

\section{Pathophysiological, histopathological and clinical characteristics}




\subsection{Symptoms}

The disease appears in young adults, but it can occur at all ages. Classical signs are represented by thrombosis (most commonly in the deep limb veins) and obstetrical complications (recurrent foetal loss and preeclampsia) (10-14). Clinically, the series of events that lead to hypercoagulability and recurrent thrombosis can affect virtually any organ system, including the following:

- Central nervous system (stroke, sinus thrombosis, seizures, chorea, reversible cerebral vasoconstriction syndrome)

- Cardiac (myocardial infarction, Libman-Sacks valvulopathy, diastolic dysfunction)

- Renal (thrombotic microangiopathy) antibodies

- Hematologic (thrombocytopenia, haemolytic anaemia)

- Pulmonary (pulmonary embolism, pulmonary hypertension)

- Dermatologic (livedo reticularis, purpura, infarcts/ulceration)

- Ocular (amaurosis, retinal thrombosis)

- Adrenal (infarction/haemorrhage)

- Musculoskeletal (avascular necrosis of bone)

- Peripheral nervous system (peripheral neuropathy including Guillain-Barré syndrome) (10-14).

A medical history of headaches or migraines could be one of the earliest manifestations of APS (15).

Recurrent thromboses are common. A very rare accelerated form of APS is catastrophic APS that occurs most frequently in women in their 30 s and can lead to massive venous thromboembolism along with respiratory failure.

\subsection{Primary and secondary APS}

The experts accorded to make the distinction between primary APS (PAPS) and APS secondary to other conditions $(1,16)$. APS may occur as isolated, without any associated condition (primary APS or in the context of a background disease, particularly autoimmune, mainly systemic lupus erythematosus (SLE) (secondary APS).

Although the major clinical manifestations and the biological features are the same in both types, they are two distinct entities with a trend for the prevalence of specific features in one and the other type of APS.

As revealed by some authors, even though there are classification criteria for SLE and APS, the distinction between primary and secondary APS can be difficult, since primary APS may 
present with proteinuria, pleurisy, seizures, psychosis, hemolytic anemia and thrombocytopenia. In 1993, Piette et al. proposed exclusion criteria for primary APS such as malar or discoid rashes, oral or pharyngeal ulceration, arthritis, pleuritis, pericarditis, proteinuria greater than $0.5 \mathrm{~g}$ per day, lymphopenia of less than $1000 \mu \mathrm{l}$, anti-DNA or antiENA antibodies, ANA of greater than 1:320, and the use of drugs known to induce aPL. However, these exclusion criteria have not been used by clinicians (17).

The differences between primary and secondary APS were considered by several reports and they concern clinical and laboratory features, genetic and histological aspects (18-28).

\subsubsection{Are they distinct?}

Primary antiphospholipid syndrome and antiphospholipid syndrome associated to lupus have several overlapping characteristics (21).

Multiorgan manifestations similar to classical typical clinical features of systemic lupus erythematosus lupus are also reported in patients with PAPS (22).

Different SLE biological features such as an autoantibody against chromatin and complement activation have been also described in patients with PAPS (22-29).

In a cohort of 108 patients Weber et al. have suggested the occurrence of an intermediate group of patients with antiphospholipid syndrome and lupus-like disease, but with features more common to PAPS (30).

Tarr et al. have suggested that PAPS could be the forerunner of SLE (23). In $7.2 \%$ of the cases in their series PAPS appeared 5.5 years before the onset of lupus (23).

In their experience, this subgroup of patients presented with more thrombotic and less inflammatory complications than SLE patients without a prior or with a following secondary APS (23).

Distinct polymorphisms of genetic factors have been associated with SLE and PAPS, suggesting that these entities are variants within a continuum of the same disease (22).

Recently, Taraborelli et al. reported in a retrospective multicentre study in one hundred fifteen patients, followed between 1983 and 2014, with a median follow-up of 18 years (range $15-30)$, that $14 \%$ of primary APS patients developed an autoimmune disease and $13(11 \%)$ a connective tissue disease (24). 
Some authors suggested that some biological markers could be an useful tool for identifying PAPS subgroup which will later became a SAPS (31).

Therefore, Andreoli et al. have suggested that antinucleosome antibodies could be predictive for outcome of PAPS evolving into SLE (31).

Medium-high titre anti-nucleosome antibodies were found in $46 \%$ of PAPS patients, and more frequently in subgroup of patients with features of "lupus like disease"(31).

\subsubsection{Clinical and laboratory features in primary and secondary APS}

As regard clinical and laboratory features in primary and secondary APS, several data are available in the literature.

Nevertheless, some difficulties in the interpretation of data from studies performed prior to updated Sydney criteria unable strong formal conclusions as regard certain distinctive features between these two entities.

In the study of Vianna et al., patients with PAPS and patients with APS plus SLE had differences which concerned autoimmune haemolytic anaemia, endocardial valve disease, neutropenia, and low C4 levels, all of which occurred more frequently in patients with APS plus SLE ( $p$ values: $<0.05,<0.005,<0.01$, and $<0.00$, respectively) (25). In their series, no patient with PAPS had either anti-DNA or anti- extractable nuclear antigen antibodies, and, moreover, these patients had a significantly lower prevalence of antinuclear antibodies (41\%) than patients with APS plus SLE (89\%) (25).

For Weber $\mathrm{H}$ et al. the main differences between PAPS and SAPS consisted in statistically significant differences for positive Coomb's test, leukopenia, lymphocytopenia, antinuclear antibodies, anti-DNA and anti ENA antibodies and hypocomplementemia (30).

It has been further suggested that the male/female ratio in PAPS is higher than in SLE and in secondary APS (25). Thrombocytopenia, haemolytic anaemia and livedo reticularis were more frequently found in patients with APS secondary to SLE, whereas arterial occlusions and recurrent foetal loss have higher frequency in PAPS (25).

Freitas MV et al reported a trend in the association of arterial thrombosis to PAPS, and of lymphopenia, antinuclear antibodies and VDRL to secondary APS (32).

Moss KE and al compared renal disease severity and outcome in three groups of patients: 20 patients with primary antiphospholipid syndrome, 25 patients with antiphospholipid 
syndrome secondary to systemic lupus erythematosus (SLE) and 275 patients with systemic lupus erythematosus SLE alone (33).

In this cohort, patients with PAPS were less likely to develop end-stage renal failure, as no patients with PAPS developed end-stage renal failure compared with $5.9 \%$ of patients with SAPS and $16.9 \%$ of patients with systemic lupus erythematosus alone (33).

In a large retrospective cohort of 637 patients Soltesz $\mathrm{P}$ et al. comparatively evaluated the clinical and laboratory features of primary and secondary to SLE APS patients (34).

Stroke was more frequently found in SAPS $(p=0.04)$; and predominantly associated to LA and $\lg G$ aCL (34).

Venous thrombosis was more frequently associated to LA $(p<0.0001)$, and coronary, peripheral artery and carotid thrombosis in patients with $\mathrm{ACL} \lg G$ and $\lg \mathrm{M}(\mathrm{p}<0.0001)(35)$. As regard fetal loss, no differences between groups were reported by some authors, (34), but these data are controversial (35-37).

Boura et al. found more miscarriages in primary APS $(p<0.05)(35)$, data in contrast, with those from a cross-sectional study of consecutive patients in the Hopkins Lupus Center (36). Therefore, the frequency of thrombosis and pregnancy loss was higher in SAPS than in primary APS in the Hopkins Lupus cohort (36).

Recurrent miscarriages, and livedo reticularis occurred more often in SAPS by other groups (38).

In the study of Marai et al. clinical features of patients with primary or secondary syndrome were similar (37). Patients with SAPS had a higher prevalence of hemolytic anemia $(28.6 \% \mathrm{~V}$ $3.3 \% ; P=0.001)$, and antinuclear antibodies (75\% v 12.9\%; $P=0.0001)$ (37).

Moreover, the authors observed that the clinical manifestations were similar in Israeli and non-Israeli patients (37).

A large diversity of clinical symptoms and immunological disturbances were more frequent in SAPS patients.

Some authors reported a higher prevalence of pulmonary embolism and deep venous thrombosis in primary APS (38). 
Chwalińska-Sadowska $\mathrm{H}$ et al. further reported that PAPS patients were younger at the onset of the disease compare to SAPS patients and that men/female ratio was lower in patients affected with SAPS (38).

A Russian prospective trial in 93 patients including 34 patients with PAPS and 59 with APS secondary to SLE (SAPS)reported that vascular manifestations were predominant in primary APS and systemic manifestations were predominant in those with SAPS (39).

Pons Estel et al. have recently focused on the primary and secondary APS similarities and differences (40). Therefore, the presence or lack of SLE might modify the clinical or serological expression of APS. Secondary APS patients with associated SLE more frequently present arthralgias, arthritis, autoimmune hemolytic anemia, livedo reticularis, epilepsy, glomerular thrombosis, and myocardial infarction (40).

The aPL (aCL, aß2GPI, LAC) antibody profile in PAPS versus SAPS has been also focused, although, little literature is available on this topic.

Different reports found that there were no differences in aPL profile between primary and secondary to SLE APS patients (34-35, 37, 39); and no correlation between the antibody titers (LA, IgG aCL, IgM aCL) and clinical manifestations (37).

Some authors reported that anti annexinV antibodies occurred more often in SAPS, and IgM aCL, LAC, anti beta2GP1, oxyLDL antibodies in primary APS (38).

In the cohort of Alarcon Segovia et al. patients with PAPS tend to have more persistently positive and higher levels of aCL than those with secondary APS (41).

In the series of Djokovic LA was more frequently reported in PAPS (42), data in contrast with results available from the larger Europhospholipid cohort (26).

$\begin{array}{llll}\text { Type of aPL } & \text { PAPS } & \text { SAPS } & \text { References } \\ \text { acL } & + \text { more positive and higher } & & 41 \\ & \text { levels } & & 42 \\ \text { Lupus anticoagulant } & + & + & 26 \\ \text { Lupus anticoagulant } & & + & 34,37,39 \\ \text { No differences } & + & & \end{array}$

Table 1. Antiphospholipid antibodies profiles in primary and secondary APS.

Several data are available from the Serbian national cohort APS study (42-45). 
In all studies of this team certain classes of aPL were associated with distinct clinical manifestations in primary and secondary APS (42-45).

The distribution of aPL in the primary APS and SLE groups revealed a highly significant difference in the presence of aCL IgG and IgM, and $\beta 2$ GPI IgG antibodies (42). Lupus anticoagulant was present alone in 47 patients (18.1\%) with primary APS and only $7(6.1 \%)$ with SLE. aCL antibodies were present alone in 43 (16.5\%) with primary APS and 22 $(19.3 \%)$ with SLE. Anti- $\beta 2$ GPI antibodies were present alone in $13(5.0 \%)$ with primary APS and 5 (4.4\%) with SLE (43).

As regard cardiac and neurological manifestations in APS, the presence of aCL IgG was more common $(p=0.001)$ in SAPS and LA in PAPS patients $(p=0.002)$. In PAPS high B2GPI IgM levels (>100PLU/ml) were more common in epilepsy $(p=0.00001)$ (43). In SAPS high B2GPI IgM levels were more common in transient ischemic attack $(p=0.029)$ and high B2GPI lgG levels (>100PLU/ml) were more common in epilepsy ( $p=0.035)$ (43).

Chorea, migraine and epilepsy occurred more often in SAPS. In SAPS statistical significant correlations were found as regard the presence of $\mathrm{aCL} \operatorname{lgG}$ and acute ischemic encephalopathy, aCL $\lg M$ and epilepsy, B2GPI IgG and chorea (43).

Headache and depression were more common in PAPS (43).

In PAPS there was statistical significance considering the presence of $\mathrm{aCL} \lg \mathrm{M}$ and migraine, and B2GPI IgM and TIA and epilepsy. LA was linked to depression, transient global amnesia and migraine in PAPS (43).

Patients with non-stable angina pectoris were more likely to develop TIA in both PAPS and SAPS, epilepsy and transient global amnesia in PAPS and acute ischemic encephalopathy in SAPS (43).

A prospective clinical study examined the association between subclasses of antiphospholipid and pulmonary manifestations in APS (45).

In SAPS, high aCL IgG levels (> $100 \mathrm{PLU} / \mathrm{mL}$ ) were more common in major pulmonary arterial thrombosis $(p=0.006)$ and medium aCL IgG levels (41-99 PLU/mL) in adult respiratory distress syndrome (ARDS; $p=0.047)$ and fibrosing alveolitis $(p=0.002)$. aCL IgG antibodies were more common in SAPS $(p=0.037)$. In PAPS, fibrosing alveolitis was more 
common in patients with medium $\beta_{2}$ GPI IgM levels $(p=0.0001)$. LA correlated with pulmonary embolism $(p=0.03)$ and microthrombosis $(p=0.03)$ in SAPS, and with pulmonary microthrombosis $(p=0.03)$ in PAPS (45).

Males were more likely to develop secondary pulmonary hypertension when diagnosed with PAPS $(p=0.019)(45)$.

As regards non criteria manifestations of APS and aPL antibody type and level, the same authors found that in PAPS, epilepsy correlated with B2GPI-IgM, migraine with aCL-IgM, and thrombocytopenia with aCL-IgM, aCL-IgG, anti B2GPI-IgG and LA (43).

Skin ulcerations occurred more frequently in Ilc category patients and in patients with high levels of aCL-IgG and anti ß2GPI-lgG. Livedo reticularis was more prominent in PAPS with high levels of aCL-lgG. Significantly higher prevalence of thrombocytopenia was observed in patients with high levels of aCL-IgG and anti B2GPI-lgG (44).

In SAPS epilepsy was related to high levels of anti B2GPI-IgM and thrombocytopenia was correlated with aCL-lgG. Skin ulcerations were more prevalent in aCL-IgM positive SAPS patients and epilepsy more frequently in SAPS patients with high levels of anti B2GPI-lgG (44).

These data are summarized in tables 2 and 3.

\begin{tabular}{|c|c|c|}
\hline Type of aPL in PAPS & Features & References \\
\hline LA & More common p 0.002 in PAPS & 42 \\
\hline LA & depression & 43 \\
\hline LA & transient global amnesia & 43 \\
\hline LA & migraine & 43 \\
\hline LA & pulmonary micro-thrombosis $(p=0.03)$ & 45 \\
\hline LA & thrombocytopenia & 44 \\
\hline anti ß2GPI IgM levels & epilepsy ( $p=0.00001)$ & 43 \\
\hline \multicolumn{3}{|l|}{ (High titers >100PLU/ml)) } \\
\hline anti B2GPI IgM & transient ischemic attack & 43 \\
\hline anti ß2GPI IgM levels & fibrosing alveolitis $(p=0.0001)$ & 45 \\
\hline (medium anti $\beta_{2}$ GPI lgM titers) & & \\
\hline
\end{tabular}


and LA

aCL-IgG and anti B2GPI-lgG

(high levels)

Skin ulcerations

44

Livedo reticularis was more prominent in

PAPS with high levels of aCL-lgG.

aCL-IgM

migraine

43

Table 2. Correlations between aPL antibodies type and clinical manifestations in PAPS

\begin{tabular}{|c|c|c|}
\hline Type of aPL in SAPS & Features & References \\
\hline aCL IgG antibodies & were more common in SAPS $(p=0.037)$. & 45 \\
\hline high aCL IgG levels (> 100 & major pulmonary arterial thrombosi & 45 \\
\hline PLU/mL) & & \\
\hline aCL IgG, & acute ischaemic encephalopathy & 43 \\
\hline aCL-IgG & thrombocytopenia & 44 \\
\hline aCL IgM & Epilepsy & 44 \\
\hline & Skin ulcerations & \\
\hline LA & correlated with pulmonary embolism $(p=0.03)$ & 45 \\
\hline LA & correlated with microthrombosis $(p=0.03$ & 45 \\
\hline high B2GPI IgM levels. & common in transient ischaemic attack $(p=0.029)$ & 43 \\
\hline high B2GPI IgG levels & epilepsy ( $p=0.035$ ). & 43 \\
\hline (>100 UI GPL) & & \\
\hline B2GPI IgG & & 45 \\
\hline
\end{tabular}

As regard traditional risk cardiovascular factors, they were comparable between patients with primary and secondary APS, except for a high frequency of low HDL-c in primary APS patients (46).

The most important and relevant data arise from the large 1000 patients Europhospholipid trial $(26,27)$. 
In the 10 year-follow-up of the "Euro-phospholipid" trial, SLE-associated APS patients presented more frequently arthralgias (31.1\% vs $8.1 \%)$ and arthritis ( $21.2 \%$ vs $2.8 \%)$, leucopenia (14.4\% vs $2.4 \%$ ), autoimmune hemolytic anemia (15.9\% vs $2.1 \%)$, livedo reticularis (21.2\% vs $6.9 \%)$, epilepsy (6.8\% vs $1.2 \%)$, glomerular thrombosis $(3.0 \%$ vs $0.2 \%)$ and myocardial infarction (3.8\% vs $1.2 \%$ ) compared with primary APS patients. Primary APS patients developed more frequently superficial thrombophlebitis ( $0 \%$ vs $1.9 \%)$ and fetal morbidity such as birth prematurity $(40.0 \%$ vs $72.3 \%)$ and intrauterine growth restriction $(1.0 \%$ vs $51.1 \%)(26)$. As regards the different autoantibodies patterns, LA, antinuclear antibodies (ANA), anti-dsDNA, anti-Ro/SSA, anti-La/SSB, anti-RNP and anti-Sm antibodies were more frequent in patients with APS associated with SLE compared with primary APS ( $p$ $<0.001)(26)$.

No lethal outcome has been observed in patients with primary APS patients as compared to SLE and APS secondary to SLE patients, suggesting a better prognosis in PAPS (33). However, no differences in survival were found in the large Europhospholipid cohort after a period of 10 years of follow-up (26).

In the "Euro-Phospholipid" project, the mortality rate was similar in both groups, as $6.8 \%$ of patients with APS associated with SLE and $7.1 \%$ of patients with primary APS had a lethal outcome (26).

However, the differences in clinical and serological manifestations reported in these series could also be related to different geographical origins (47).

Mejía-Romero $\mathrm{R}$ et al reported that latin American mestizo patients with primary APS have a wide variety of clinical and immunological manifestations with several differences in their prevalence in comparison with European white patients (47).

Several clinical manifestations were more prevalent in the Latin American mestizo 100 patients of their multinational cohort than in the European patients (transient global amnesia, pulmonary microthrombosis, arthralgias, and early pregnancy losses). Adversely, deep venous thrombosis, stroke, pulmonary embolism, and thrombocytopenia were more prevalent in European white patients (47).

\subsubsection{Genetic in primary and secondary APS}

Development of clinical features of APS in monozygotic twins suggest a genetic basis in the pathogenesis of anti-phospholipid syndrome $(48,49)$. 
Freitas MVC et al reported a trend to association with DR53-asssociated alleles that was observed in PAPS patients as compared with secondary APS (32). HLA-DRB1 and HLADQB1 profiles of primary and secondary APS are different, as for primary APS the HLA-DR7 is a genetic marker and for secondary APS the genetic markers are HLA-B8, HLA-DR2, HLA-DR3 (20).

A genome wide analysis has identified several suggestive novel loci for APS; however, related to the low number of primary APS, no comparison could be performed between primary and secondary APS (50).

Muller-Calleja $\mathrm{N}$ et al have confirmed by genome wide analysis the significant associations of anti-B2GP1 IgG and APOH on chromosome 17, previously shown by candidate genes approaches, and of anti-domain 1 and MACROD2 on chromosome 20; and that antiphospholipid antibodies induce the expression of NAV3 in monocytes and endothelial cells (51).

It has been recently shown that MHC class II alleles have not only an impact on the quantitative production of aPL antibodies but also on their pathogenicity (52).

A recent study in a Japanese population with obstetric APS focussing on lupus anticoagulant demonstrated that a specific genotype of TSHR and C1D genes can be as risk factor for obstetric APS (53).

Recent data have shown decreased number of circulating CD4+CD25+Foxp3+ Treg and CD3-CD19+ B cells in patients with systemic lupus erythematosus and secondary antiphospholipid syndrome, in SLE and primary APS (54).

Microarray expression profiling performed in monocytes further validated by RT-PCR of selected genes and western blot identified 555, 1224 and 518 genes differentially expressed in monocytes from SLE, APS plus SLE and APS patients compared with controls (55). Among them $25-30 \%$ of differentially expressed genes were related to atherosclerosis and cardiovascular disease. Each disease had her own atherosclerosis and cardiovascular disease /Inflammation-related gene signature. The main differences between APS and SLE were the alterations in mitochondria biogenesis and function and oxidative stress found in APS; and the interferon signature and various genes mediating atherosclerotic/inflammatory signaling found in APS plus SLE and SLE patients. IgG-anticardiolipin (aCL) titers independently predicted both atherosclerotic and thrombosis in APS plus SLE (55). 


\subsubsection{Histological features in primary and secondary APS}

The kidney appears to be a major target organ in both primary and secondary APS.

The renal manifestations of APS may result from thrombosis occurring at any location within the renal vasculature, that is, in the renal artery trunk or branches, intraparenchymal arteries and arterioles, glomerular capillaries, and the renal veins. The spectrum of these manifestations includes renal artery stenosis and/or malignant hypertension, renal infarction, renal vein thrombosis, thrombotic microangiopathy, increased allograft vascular thrombosis, and reduced survival of renal allografts. More recently no thrombotic conditions like glomerulonephritis have also been reported.

The role of biopsy is essential as inflammatory and thrombotic lesions require different therapeutic approaches (56).

Sciascia $S$ et al have reported that the renal manifestations in APS are various and that renal prognosis is affected by the presence of aPLs in patients with lupus nephritis (56).

It has been reported that primary APS-associated nephropathy has slower progression and rarely leads to end-stage renal failure (57).

The comparison between primary and secondary APS histological renal lesions revealed that glomerular thrombotic lesions were present in both types of APS, but immune complex disease were considered as specific to secondary APS (58).

All the data as regard current knowledge with respect to differences and potential differences between primary and secondary APS are summarized in the table 4.

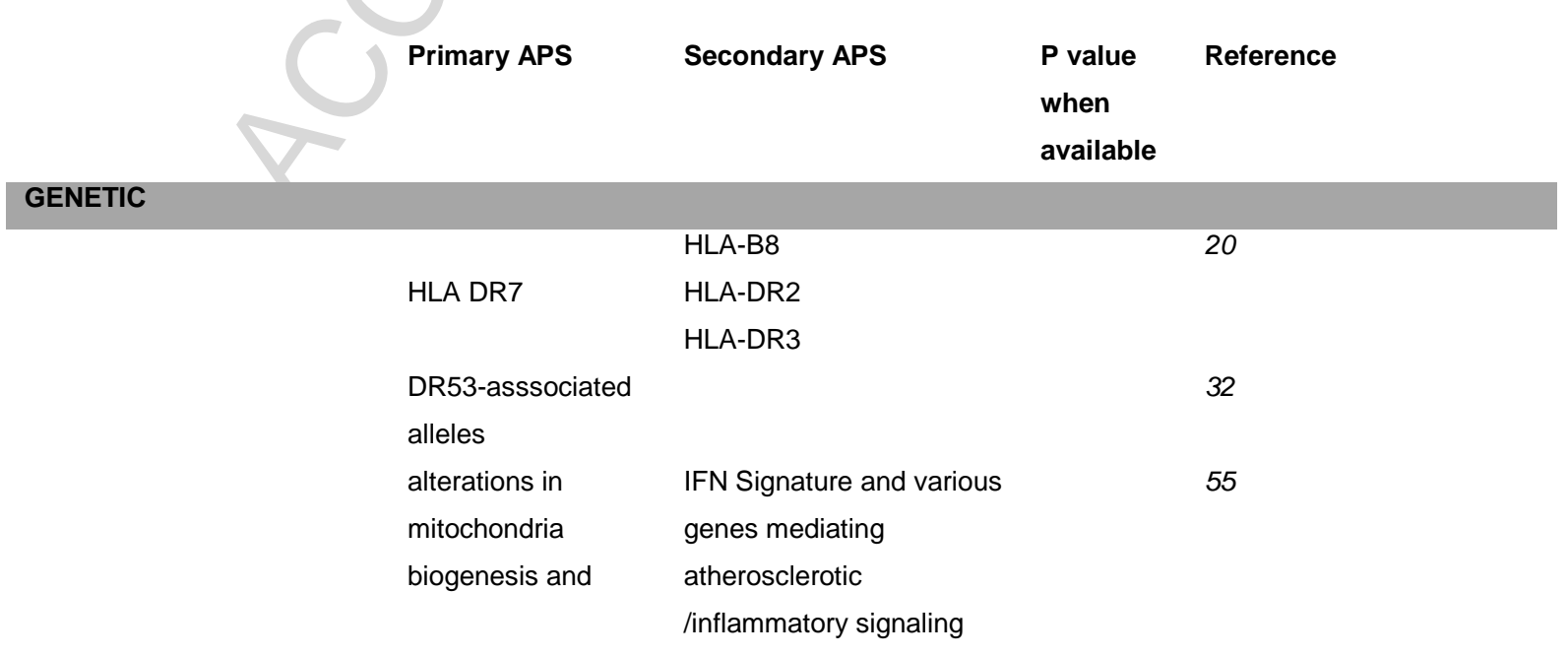


function and

oxidative stress.

decreased

decreased numbers of

54

numbers of

circulating

circulating

CD4+CD25+Foxp3 + Treg

CD4+CD25+Foxp3+

and CD3-CD19+ $B$ cells

Treg and CD3

CD19+ B cells

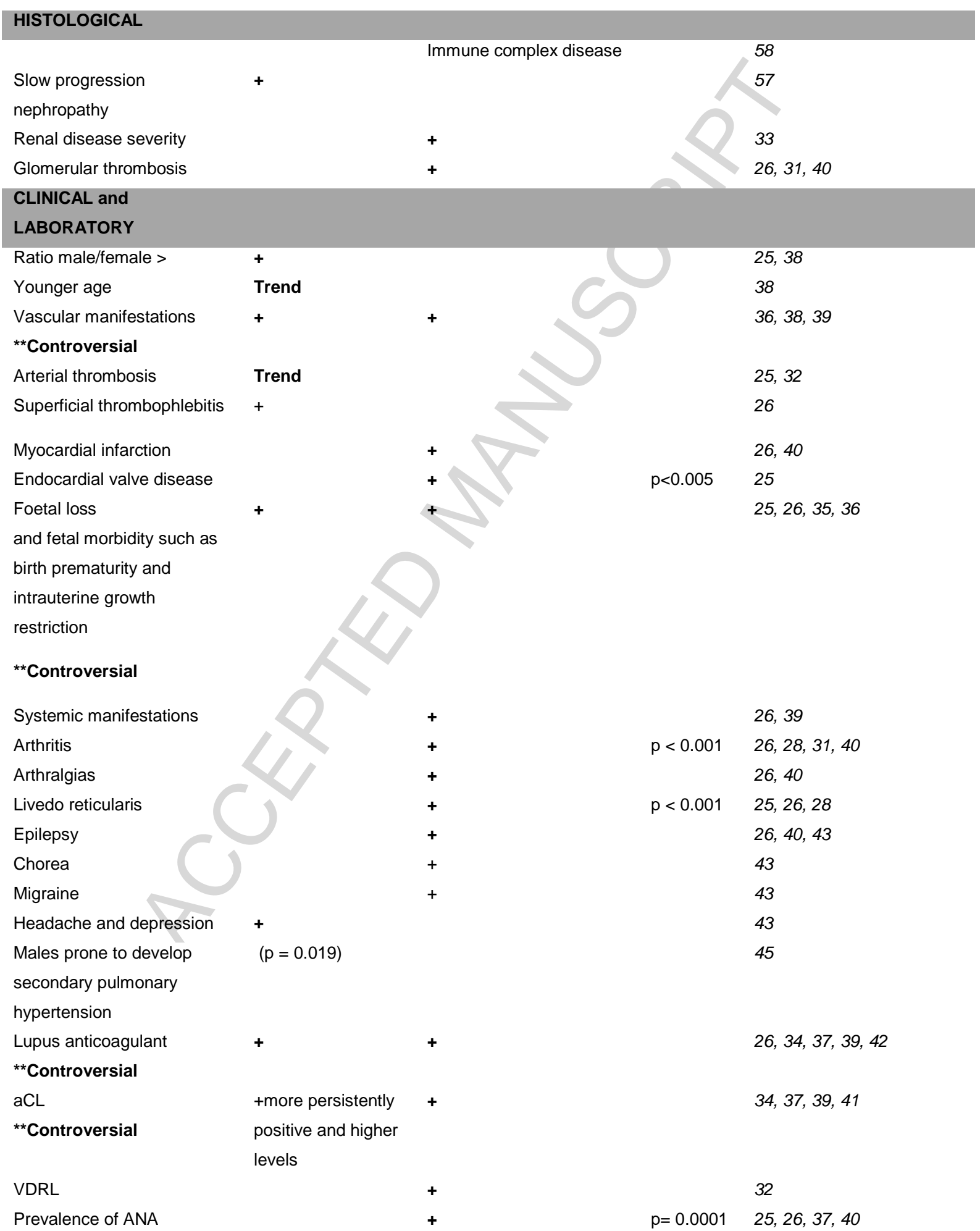




\begin{tabular}{|c|c|c|c|}
\hline $\begin{array}{l}\text { Presence of anti DNA } \\
\text { antibodies }\end{array}$ & + & & $25,26,40$ \\
\hline $\begin{array}{l}\text { Anti-Ro/SSA, anti-La/SSB, } \\
\text { anti-RNP and anti-Sm } \\
\text { antibodies }\end{array}$ & + & & 26 \\
\hline Low C4 & + & $<0.001$ & 25,40 \\
\hline $\begin{array}{l}\text { Autoimmune hemolytic } \\
\text { anemia }\end{array}$ & + & $\begin{array}{l}p<0.05 \\
p=0.001\end{array}$ & $25,26,31,37$ \\
\hline Leucopenia & + & $\mathrm{p}<0.001$ & 26,28 \\
\hline Neutropenia & + & $\mathrm{p}<0.01$ & 25 \\
\hline Lymphopenia & + & & 32,40 \\
\hline Thrombocytopenia & + & $p<0.001$ & 25,28 \\
\hline Low HDLc & + & & 46 \\
\hline Worse prognosis & + & & 26,33 \\
\hline
\end{tabular}

Table 4. Summary of genetical, histological, clinical and biological features in primary and secondary APS.

\section{Conclusion}

According to these findings, there are several features that could characterize primary APS as compared to secondary APS.

Nevertheless, these data should be interpreted with much caution, especially with respect to biological and clinical features, but also to histological differences, as most of these studies were performed before the update of classification criteria in APS (1).

It should not be forgotten that for some authors PAPS and SLE is one single entity with various manifestations (22).

Based on recent data and according to Sidney diagnosis criteria of APS, the features that could allow the distinction between primary and secondary APS are mainly the presence of systemic manifestations in SAPS such as arthralgias and arthritis, vascular manifestations and particularly myocardial infarction, livedo reticularis, epilepsy, chorea, migraine, leucopenia, autoimmune hemolytic anemia.

Moreover, glomerular thrombosis and more severe renal disease are observed in secondary APS patients $(26,31,40)$, as well as probably more frequent renal lesions with immune complex disease (58). 
In primary APS a higher percentage of superficial venous thrombosis (26), as well as a slower progression nephropathy are observed (57).

Additional features such as headache and depression, and secondary pulmonary hypertension were reported in some series as more frequently prevalent in PAPS $(43,45)$.

A trend for younger age and predominant male/female ratio could be observed by some authors in primary $\operatorname{APS}(25,38)$.

As regard the aPL profiles in primary and secondary APS, data as regards LA and aCL are controversial $(26,42,34,37,39)$.

Nevertheless, autoantibodies patterns are different in primary and secondary APS:

antinuclear antibodies (ANA), anti-dsDNA, anti-Ro/SSA, anti-La/SSB, anti-RNP and anti-Sm antibodies being more frequent in patients with APS associated with SLE compared with primary APS $(p<0.001)(26)$.

However, the most important features allowing the classification in primary and secondary APS are genetical. There is an increased body of evidence of genetical differences between these two entities.

Therefore, the main differences between PAPS and SAPS are related to their genetical features: alterations in mitochondria biogenesis and function and oxidative stress in PAPS and IFN signature and various genes mediating atherosclerotic/inflammatory signaling in secondary APS (55).

Future studies on the genetic factors associated with SLE and PAPS may allow the characterisation of these entities and identify if there are specific genetic features in PAPS which evolve into SLE.

Acknowledgments to Professor CGM KALLENBERG and to Professor J RAND for their valuable remarks and suggestions. 


\section{References}

1. Miyakis S, Lockshin MD, Atsumi T, Branch DW, Brey RL, Cervera R et al. International consensus statement on an update of the classification criteria for definite antiphospholipid syndrome (APS). J Thromb Haemost 2006;4:295-306.

2. Urbanus RT, Derksen RH, de Groot PG. Platelets and the antiphospholipid syndrome. Lupus 2008;17:888-94.

3. Liestol L, Sandset PM, Mowinckel MC, Wisloff. Activated protein C resistance determined with a thrombin generation-base test is associated with thrombotic events in patients with lupus anticoagulants. J Thromb Haemost 2007;5:2204-10.

4. Kinev AV, Roubey RA. Tissue factor in the antiphospholipid syndrome. Lupus 2008;17:952-8.

5. Pierangeli SS, Girardi G, Vega-Ostertag M, Liu X, Espinola RG, Salmon J. Requirement of activation of complement $\mathrm{C} 3$ and $\mathrm{C} 5$ for antiphospholipid antibody-mediated thrombophilia. Arthritis Rheum 2005;52:2120-4.

6. Rand JH, Wu XX, Andree HA, Lockwood CJ, Guller S, Scher J et al. Pregnancy loss in the antiphospholipid antibody syndrome- a possible thrombogenic mechanism. N Engl J Med 1997; 337: 154-60.

7. De Laat B, Wu XX, van Lummel M, Derksen RH, De Groot PG, Rand JH. Correlation between antiphospholipid antibodies that recognize domain I of beta2-glycoprotein I and a reduction in the anticoagulant activity of annexinA5. Blood 2007;109:1490-4.

8. Rand JH, Wu XX, Quinn AS, Chen PP, McCrae KR, Bovill EG, et al. Human monoclonal antiphospholipid antibodies disrupt the annexin A5 anticoagulant crystal shield on phospholipid bilayers: evidence from atomic force microscopy and functional assay. Am J Pathol 2003;163:1193-2000.

9. Rand JH, Wu XX, Quinn AS, Taatjes DJ. Resistance to annexin A5 anticoagulant activity: a thrombogenic mechanism for the antiphospholipid syndrome. Lupus 2008;17:922-30.

10. Arachchillage DRJ, Laffan M. Pathogenesis and management of antiphospholipid syndrome. Br J Haematol 2017;178:181-95.

11. Merashli M, Noureldine MH, Uthman I, Khamashta M. Antiphospholipid syndrome: an update. Eur J Clin Invest 2015;45:653-62.

12. Pericleous C, Ferreira I, Borghi O, Pregnolato F, McDonnell T, Garza-Garcia A, et al. Measuring IgA Anti-B2-Glycoprotein I and IgG/lgA Anti-Domain I Antibodies Adds Value to Current Serological Assays for the Antiphospholipid Syndrome. Plos ONE 2016;11: e0156407. 
13. Stojanovich L, Djokovic A, Kontic M. Antiphospholipid-mediated thrombosis: interplay between type of antibodies and localisation of lung, and cardiovascular incidences in primary antiphospholipid syndrome. Clin Exp Rheumatol 2015;33:531-6.

14. Abreu MM, Danowski A, Wahl DG, Amigo MC, Tektonidou M, Pacheco MS et al. The relevance of "non-criteria" clinical manifestations of antiphospholipid syndrome: 14th International Congress on Antiphospholipid Antibodies Technical Task Force Report on Antiphospholipid Syndrome Clinical Features. Autoimmun Rev 2015;14:401-14.

15. Noureldine MHA, Haydar AA, Berjawi A, Elnawar R, Sweid A, Khamashta MA et al. Antiphospholipid syndrome (APS) revisited: Would migraine headaches be included in future classification criteria? Immunol Res 2017;65:230-41.

16. Asherson RA, Cervera R. 'Primary', 'secondary' and other variants of the antiphospholipid syndrome. Lupus 1994;3:293-8.

17. Piette JC, Wechsler B, Frances C, Papo T, Godeau P. Exclusion criteria for primary antiphospholipid syndrome. J Rheumatol 1993;20:1802-4.

18. Harris EN, Pierangeli SS. Primary, Secondary, Catastrophic Antiphospholipid Syndrome: is there a difference? Thromb Res 2004;114:357-61.

19. Mackworth-Young C. Primary Antiphospholipid syndrome: A distinct entity? Autoimunity Reviews 2006; 5:70-5.

20. Kapitany A, Tarr T, Gyetvai A, Szodoray P, Tumpek J, Poor G et al. Human leukocyte antigen-DRB1 and-DQB1 genotyping in lupus patients with and without antiphospholipid syndrome. Ann N Y Acad Sci 2009;1173:545-51.

21. Grossman JM. Primary versus secondary antiphospholipid syndrome: is this lupus or not? Curr Rheumatol Rep. 2004 ;6:445-50.

22. Shoenfeld Y, Meroni PL, Toubi E. Antiphospholipid syndrome and systemic lupus erythematosus: are they separate entities or just clinical presentations on the same scale? Curr Opin Rheumatol 2009;21:495-500.

23. Tarr T, Lakos G, Bhattoa HP, Szegedi G, Shoenfeld Y, Kiss E. Primary antiphospholipid syndrome as the forerunner of systemic lupus erythematosus. Lupus 2007;16:324-8.

24. Taraborelli M, Reggia R, Dall'Ara F, Fredi M, Andreoli L, Gerosa M et al. Longterm Outcome of Patients with Primary Antiphospholipid Syndrome: A Retrospective Multicenter Study. J Rheumatol 2017;44:1165-72. 
25. Vianna JL, Khamashta MA, Ordi-Ros J, Font J, Cervera R, Lopez-Soto A et al. Comparison of the primary and secondary antiphospholipid syndrome: a European multicenter study of 114 patients. Am J Med 1994;96:3-9.

26. Cervera R, Serrano R, Pons-Estel GJ, Ceberio-Hualde L, Shoenfeld Y, de Ramón $\mathrm{E}$, et al. Morbidity and mortality in the antiphospholipid syndrome during a 10year period: a multicentre prospective study of 1000 patients. Ann Rheum Dis 2015;74:1011-8.

27. Cervera R, Khamashta MA, Shoenfeld Y, Camps MT, Jacobsen S, Kiss E et al. for the Europhospholipid Project Group. Morbidity and mortality in the antiphospsholipid syndrome during a 5 year period: a multicentre prospective study of 1000 patients. Ann Rheum Dis 2009;68:1428-32.

28. Cervera R, Piette JC, Font J, Khamashta MA, Shoenfeld Y, Camps MT et al. Antiphospholipid syndrome: clinical and immunologic manifestations and patterns of disease expression in a cohort of 1,000 patients. Arthritis Rheum 2002;46:1019-27.

29. Tincani A, Andreoli L, Chighizola C, Meroni PL. The interplay between the antiphospholipid syndrome and systemic lupus erythematosus. Autoimmunity 2009;42:257-9

30. Weber M, Hayem G, De Bandt M, Seifert B, Palazzo E, Roux S et al. Classification of an intermediate group of patients with antiphospholipid syndrome and lupuslike disease: primary or secondary antiphospholipid syndrome? J Rheumatol. 1999;26:2131-6.

31. Andreoli L, Pregnolato F, Burlingame RW, Fanelli V, Allegri F, Radice A et al. [Primary antiphospholipid syndrome evolving into systemic lupus erythematosus: may antinucleosome antibodies be predictive? Reumatismo 2008;60(3):185-91.

32. Freitas MV, da Silva LM, Deghaide NH, Donaldi EA, Louzada-Junior P. Is HLA class II susceptibility to primary antiphospholipid syndrome different from susceptibility to secondary antiphospholipid syndrome? Lupus 2004; 13:125-31.

33. Moss KE, Isenberg DA. Comparison of renal disease severity and outcome in patients with primary antiphospholipid syndrome, antiphospholipid syndrome secondary to systemic lupus erythematosus (SLE) and SLE alone. Rheumatology (Oxford). 2001;40:863-7.

34. Soltész P, Veres K, Lakos G, Kiss E, Muszbek L, Szegedi G. Evaluation of clinical and laboratory features of antiphospholipid syndrome: a retrospective study of 637 patients. Lupus 2003;12:302-7. 
35. Boura P, Tselios K, Skendros P, Kountouras J. Antiphospholipid syndrome in Greece: clinical and immunological study and review of the literature. Angiology 2004;55:421-30.

36. Danowski A, de Azevedo MN, de Souza Papi JA, Petri M. Determinants of risk for venous and arterial thrombosis in primary antiphospholipid syndrome and in antiphospholipid syndrome with systemic lupus erythematosus. J Rheumatol 2009;36:1195-9.

37. Marai I, Levi Y, Godard G, Shoenfeld Y. Following 90 patients with antiphospholipid syndrome with antibody titers and correlations with clinical manifestations: symptoms of the disease, a new antibody and correlations with clinical manifestations in the Israeli population. Harefuah 2001;140:495-500, 565.

38. Chwalińska-Sadowska H, Meissner M, Wudarski M, Zabek J, Wojciechowska B. Antiphospholipid syndrome (APS) primary (PAPS) and secondary (SAPS). Pol Arch Med Wewn 2006;115:401-6.

39. Sulut'ian AE, Chapaeva NN, Shirinskiĩ VS, Kozhevnikov VS, Kozlov VA. Clinical and immunological characteristics of primary and secondary antiphospholipid syndrome. Klin Med (Mosk) 2004;82:39-43.

40. Pons-Estel GJ, Andreoli L, Scanzi F, Cervera R, Tincani A. The antiphospholipid syndrome in patients with systemic lupus erythematosus. J Autoimmun 2017 Jan;76:10-20.

41. Alarcón-Segovia D, Cabral AR. The anti-phospholipid antibody syndrome ; clinical and serological aspects. Baillieres Best Pract Res Clin Rheumatol. 2000;14:13950.

42. Djokovic A, Stojanovich L, Kontic M, Stanisavljevic N, Radovanovic S, Marisavljevic D. Association between cardiac manifestations and antiphospholipid antibody type and level in a cohort of Serbian patients with primary and secondary antiphospholipid syndrome. Isr Med Assoc J 2014;16:162-7

43. Stojanovich L, Kontic M, Smiljanic D, Djokovic A, Stamenkovic B, Marisavljevic D. Association between non-thrombotic neurological and cardiac manifestations in patients with antiphospholipid syndrome. Clin Exp Rheumatol 2013;31:756-60.

44. Stojanovich L, Kontic M, Djokovic A, Marisavljevic D, Ilijevski N, Stanisavljevic N et al. Association between systemic non-criteria APS manifestations and antibody type and level: results from the Serbian national cohort study. Clin Exp Rheumatol 2013;31:234-42. 
45. Stojanovich L, Kontic M, Djokovic A, Ilijevski N, Stanisavljevic N, Marisavljevic D. Pulmonary events in antiphospholipid syndrome: influence of antiphospholipid antibody type and levels. Scand J Rheumatol 2012;41:223-6.

46. Ribeiro AR, Carvalho JF. Traditional risk factors for cardiovascular disease in primary antiphospholipid syndrome (APS) when compared with secondary APS: a study with 96 patients. Acta Reumatol Port 2010;35:36-41.

47. Mejía-Romero R, García-Carrasco M, Galarza-Maldonado C, Santos P, MendozaPinto C, Escárcega RO et al. Primary antiphospholipid syndrome in Latin American mestizo patients: clinical and immunologic characteristics and comparison with European patients. Clin Rheumatol 2008;27:891-7.

48. Ravindran V, Rajendran S, Elias G. Primary antiphospholipid syndrome in monozygotic twins. Lupus 2013;22:92-4.

49. Cevallos R, Darnige L, Arvieux J, Veyssier P, Gruel Y. Antiphospholipid and antibeta 2 glycoprotein I antibodies in monozygotic twin sisters. J Rheumatol 1994;21:1970-1.

50. Kamboh MI, Wang X, Kao AH, Barmada MM, Clarke A, Ramsey-Goldman R et al. Genome wide association of antiphospholipid antibodies. Autoimmune Diseases 2013;2013:761046.

51. Muller-Calleja N, Rossmann H, Muller C, Wild P, Blankerberg S, Pfeiffer N et al. Antiphospholipid antibodies in a large population-based cohort: genome-wide associations and effects on monocytes gene expression. Thromb Haemost 2016; 116:115-23.

52. Papalardo E, Romay-Penabad Z, Willis R, Christadoss P, Carrera-Marin AL, Reyes-Maldonado E et al. Major histocompatibility complex class II alleles influence induction of pathogenic antiphospholipid antibodies in a mouse model a thrombosis. Arthritis Rheumatol 2017; 69:2052-61.

53. Sugiura-Ogasawara M, Mae Y, Kawashima M, Toyo-Oka L, Khor SS, Sawai H et al. The first genome-wide association study identifying new susceptibility loci for obstetric antiphospholipid syndrome. J Hum Genet 2017;62:831-8.

54. Dal Ben ER, do Prado CH, Baptista TS, Bauer ME, Staub HL. Patients with systemic lupus erythematosus and secondary antiphospholipid syndrome have decreased numbers of circulating CD4+CD25+Foxp3+ Treg and CD3-CD19+ B cells. Rev Bras Reumatol 2014;54:241-6.

55. Perez-Sanchez C, Barbarroja N, Messineo S, Ruiz-Limon P, Rodriguez-Ariza A, Jimenez-Gomez Y. Gene profil ing reveals specific molecular pathways in thepathogenesis of atherosclerosis and cardiovascular disease in 
antiphospholipid syndrome, systemic lupus erythematosus and antiphospholipid syndrome with lupus. Ann Rheum Dis 2015;74:1441-9.

56. Sciascia S, Cuadrado MJ, Khamashta M, Roccatello D. Renal involvement in antiphospholipid syndrome. Nat Rev Nephrol 2014; 10:279-89

57. Saracino A, Ramunni A, Pannrale G, Coratelli P. Kidney disease associated with primary antiphospholipid syndrome: clinical signs and histopathological features in an case experience of five cases. Clin Nephrol 2005;63:471-6.

58. Uthman I, Khamashta M. Antiphospholipid syndrome and the kidneys. Semin Arthritis Rheum 2006;35:360-7. 